\title{
CITRICULTURA DESENVOLVIDA NA AGRICULTURA DE BASE FAMILIAR DO MUNICÍPIO DE RUSSAS, CEARÁ
}

\author{
Kassio Ewerton Santos Sombra ${ }^{1 *}$, Alexandre Caique Costa e Silva ${ }^{1}$, Francisco Leandro \\ Costa Loureiro ${ }^{1}$, Débora Costa Bastos ${ }^{2}$
}

\footnotetext{
${ }^{1}$ Graduando em agronomia pelo Instituto Federal de Educação, Ciência e Tecnologia do Ceará - IFCE, campus Limoeiro do Norte, membro do Núcleo de Pesquisa em Citros (NPCitrus) e Grupo de Estudos em Agricultura Sustentável (GEAS), Limoeiro do Norte/CE, *E-mail: npcitrus.ceara @ gmail.com

${ }^{2}$ Pós-doutora em fisiologia vegetal e pesquisadora da Empresa Brasileira de Pesquisa Agropecuária EMBRAPA, Embrapa Semiárido, CPATSA, Petrolina/PE.
}

RESUMO: O Brasil é o maior produtor mundial de laranjas doces [Citrus sinensis (L.) Osbeck]. O município de Russas sobressaiu-se historicamente na produção de laranja doce, cultivando uma variedade nativa, a "laranja de Russas". O trabalho levantou e caracterizou os principais aspectos e técnicas empregadas pelos agricultores familiares na implantação e desenvolvimento inicial dos pomares cítricos. O trabalho compreendeu de abril/2013 a maio/2015, em propriedades de agricultura familiar com pomares cítricos implantados entre 2012-2014, onde caracterizou-se o produtor, a propriedade, o pomar cítrico e aspectos agronômicos. Os agricultores possuem média de 49 anos, sendo que 56,66\% se dedicam exclusivamente a agricultura e a área total média das propriedades é de 3,35 ha. Os pomares cítricos variam de 0,12 ha a 0,52 ha, em média com 142 plantas/propriedade, espaçadas principalmente 4 x 3m (33\%), predomina o cultivo de laranja doce (77\%, 5.046 mudas), mas constata-se também a lima ácida (9\%) e demais espécies (tangerina, pomelo e limão, $14 \%$ ). Constatou-se alta diversidade copas/porta-enxertos, distinguindo-se do principal polo citrícola (SP). Ocorre predominância de adubação orgânica; gotejamento e utilização de defensivos naturais no controle de pragas. Constatou-se alta ocorrência de minadora-dasfolhas do citros (Phyllocnistis citrella Station.) e cochonilhas em geral. Porém, não registrou-se pragas-chave como mosca negra (Aleurocanthus woglum Ashby.), nem gomose (Phytophthora spp.). A citricultura desenvolvida na agricultura familiar de Russas-CE sobressai-se pela alta diversificação de cultivares, diversidade de atividades concomitantes e baixa incidência de pragas. Cita-se o baixo poder aquisitivo e a baixa tecnologia empregada como pontos negativos, podendo sanar-se com assistência técnica e disponibilidade de crédito rural.

Palavras-chave: Agricultura familiar. Citros. Cultivares. Pomares.

\section{CITRICULTURE DEVELOPED IN FAMILY AGRICULTURE OF THE MUNICIPALITY OF RUSSAS, CEARÁ}

\begin{abstract}
Brazil is the largest producer of sweet oranges [Citrus sinensis (L.) Osbeck]. The municipality of Russas stood out historically in sweet orange production, cultivating a native variety, the "orange the Russas" The work up and characterized the main aspects and techniques employed by farmers in the implementation and initial development of citrus
\end{abstract}

Cultura Agronômica, Ilha Solteira, v.25, n.3, p.303-316, 2016 
groves. The work included April / 2013 to May / 2015 in family farming properties with citrus orchards located between 2012-2014, where the producer was characterized, property, citrus orchard and agronomic aspects. Farmers have an average of 49 years, and $56.66 \%$ were engaged exclusively in agriculture and average total area of holdings is $3.35 \mathrm{ha}$. The citrus groves ranging from 0.12 ha to 0.52 ha, with an average of 142 plants / property, spaced $4 \mathrm{~m} \times 3 \mathrm{~m}$ mainly (33\%), sweet orange predominates cultivation (77\%, 5.046 seedlings), but also acid lime (9\%) and other species (tangerine, grapefruit and lemon, 14\%). It found high diversity canopy / rootstock, distinguishing the main polo citrus (SP). It occurs predominantly organic fertilizer; drip and use of natural pesticides to control pests. It found high occurrence of leaf miner-of-leaves of citrus (Phyllocnistis Citrella Station.) And scale insects in general. But not enrolled key pests such as black fly (Aleurocanthus woglum Ashby.) or gummosis (Phytophthora spp.). The citrus industry developed in family agriculture of Russas - CE stands by high diversification of crops, diversity of concurrent activities and low incidence of pests. Mention is the low purchasing power and low technology employed as negative points and can heal with technical assistance and availability of rural credit.

Key words: Citrus. Cultivars. Family farming. Orchards.

\section{INTRODUÇÃO}

Os citros pertencem à família Rutácea, com principais gêneros: Citrus (L.), Poncirus (Raf.) e Fortunella (Swing.). A citricultura compreende o cultivo de laranjeiras doces $[C$. sinensis (L.) Osbeck], tangerineiras (diversas espécies), limoeiros [C. limon (L.) Burm. f.], limeiras ácidas e doces (diversas espécies), pomeleiros (C. paradisi Macfad.) e cidreiras $(C$. medica L.) (SANTOS FILHO et al., 2005; PIO et al., 2005; CUNHA SOBRINHO et al., 2013). Desde a década de 80, o Brasil ocupa posição de maior produtor mundial de frutos cítricos, atingindo quase $59 \%$ de crescimento na década de 80 , saltando de 575.249 hectares para 912.996 ha colhidos (ALMEIDA; PASSOS, 2011; IBGE, 2015). Em 2015, registrou-se a área colhida de cerca de 652.131 ha, com produção de 14.693 .496 ton. de laranja e rendimento médio de 22,53 ton./ha, tendo o Sudeste e o Nordeste como principais regiões produtoras. A região Nordeste responde por cerca de 18,9\% da área colhida e 11,3\% da produção nacional, produzindo cerca de 1.658 .588 ton. de frutas, com rendimento médio de 13,67 ton./ha (IBGE, 2015).

O município de Russas sobressaiu-se historicamente pelo cultivo de uma variedade nativa de laranja doce, a "Laranja de Russas", recebendo título de "Terra da Laranja Doce". Acredita-se que a origem da laranjeira de "Russas" [C. sinensis (L.) Osbeck] possa associarse com a introdução de sementes de laranja pelos jesuítas portugueses, logo após o descobrimento (PASSOS et al., 2013). Relatos da década de 1930 já mencionavam a Laranja de Russas, cultivada através de mudas seminais (pés francos) e irrigação por inundação na agricultura familiar. Porém, entre as cheias que ocorreram nos anos de 1974 e 1985, a doença "gomose" (Phytophthora spp.) atingiu cerca de $90 \%$ dos pomares do 
município, constituídos de "laranjeiras de Russas" altamente susceptíveis, levando ao declínio da cadeia produtiva.

O trabalho objetivou-se em levantar e caracterizar os principais aspectos e técnicas empregadas pelos agricultores familiares de Russas na implantação e desenvolvimento inicial dos pomares cítricos.

\section{MATERIAL E MÉTODOS}

A pesquisa foi conduzida entre abril de 2013 e maio de 2015 . Foram 30 propriedades estudadas de pequeno porte de agricultura familiar com pomares cítricos, distribuídas em 16 localidades do município de Russas - CE (Figura 1), seis apenas na localidade chamada "Poço Verde" (Tabela 1). Russas é um município cearense localizado na mesorregião do Vale do Jaguaribe, área circunscrita às coordenadas geográficas $4^{\circ} 56^{\prime} 24^{\prime \prime} \mathrm{S}, 37^{\circ} 58^{\prime} 33^{\prime \prime} \mathrm{W}$, com altitude de 20,51m acima do nível do mar, clima tropical quente semiárido, insere-se no bioma caatinga, com regime pluviométrico médio de 857,7 mm, variando de 548 a $992 \mathrm{~mm}$, distribuídas em duas estações, uma chuvosa, de janeiro a julho, e outra seca, de agosto a dezembro. Temperatura média anual aproxima-se de $27.1^{\circ} \mathrm{C}$, oscilando entre $22.3^{\circ} \mathrm{C}$ e $34.8^{\circ} \mathrm{C}$ e umidade relativa do ar variando de $44 \%$ a $85 \%$.

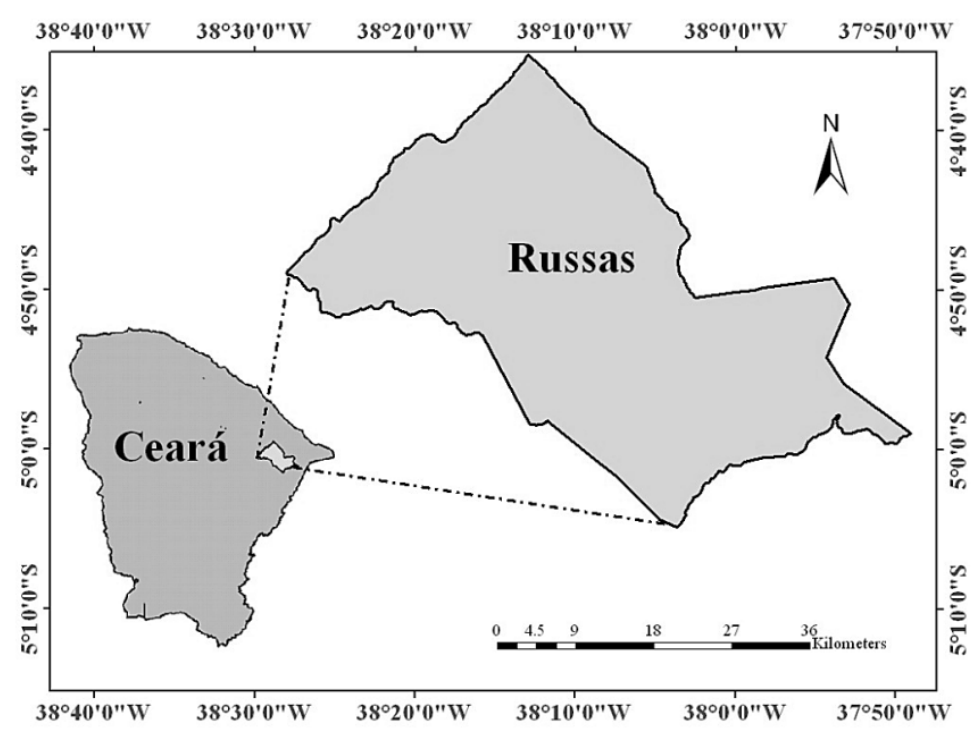

Figura 1. Caracterização da área de estudo, município de Russas, Ceará.

A amostra constitui-se do total de pomares cítricos implantados entre os anos de 2012 e 2014 em pequenas propriedades rurais do município de Russas através da parceria entre a EMBRAPA - Mandioca e Fruticultura Tropical (Cruz das Almas, Bahia), EMBRAPA Semiárido (Petrolina, Pernambuco) e a Secretaria de Agricultura de Russas (SEAGRI RUSSAS) (Tabela 1). A citricultura no município ainda se constitui basicamente de uma divisão entre os pomares remanescentes da década de 80 , formados predominantemente de plantas seminais (pés francos) propagadas em sua maioria pelos (as) próprios (as) agricultores (as), e os pomares atendidos pelo Projeto de Revitalização da Citricultura no Vale do Jaguaribe. Esse projeto é de origem e gestão popular, contando com o apoio de 
instituições de ensino, pesquisa e extensão, constituídos em sua maioria por combinações copa/porta-enxerto diversas, produzidas por meio da técnica de enxertia (borbulhia) e doadas pela Embrapa aos pequenos citricultores, em sua maioria agricultores (as) familiares. Estima-se que atualmente o município possua entre sete e dez mil laranjeiras, das quais metade está presente nas propriedades acompanhadas no presente estudo.

Tabela 1. Distribuição dos pomares cítricos implantados entre 2012 e 2014 por localidades rurais, Russas, Ceará.

\begin{tabular}{lc}
\hline \multicolumn{1}{c}{ Localidade } & $\begin{array}{c}\mathbf{N}^{\mathbf{0}} \text { Pomares } \\
\text { cítricos }\end{array}$ \\
\hline Bento Pereiro & 2 \\
Boa Vista & 1 \\
Bom Sucesso & 1 \\
Borges de Russas & 2 \\
Búia & 2 \\
Carpina & 1 \\
Córrego da Catita & 2 \\
Futuro & 1 \\
Ipepacunha & 1 \\
Melancias & 1 \\
Pau Branco & 4 \\
Pau D'arco & 1 \\
Poço Redondo & 2 \\
Poço Verde & 6 \\
Sítio Canto & 2 \\
Tourão & 1 \\
\hline \multicolumn{2}{c}{ Total } \\
\hline
\end{tabular}

A pesquisa foi realizada através da técnica de observação direta intensiva, realizandose entrevistas semiestruturadas com auxílio de questionários (MARCONI et al., 2007). Buscou-se avaliar parâmetros quantitativos e qualitativos do sistema citrícola inserido na agricultura familiar, caracterizando-se o produtor (gênero, idade média e composição familiar), a propriedade (área total e utilização desta área para agropecuária), pomar cítrico (área, espaçamento, número médio de plantas, espécies cítricas e distribuição das cultivares, copa e porta-enxerto, adotadas) e aspectos agronômicos (adubação de formação/cobertura; tratos culturais; irrigação; ocorrência e controle de pragas/doenças. Para ocorrência de pragas, realizaram-se inicialmente amostragens mensais, em função do número de pomares amostrados e da mão de obra disponível, porém, quando se constatava a presença de insetos pragas na área, elevava-se a atenção sobre esta, reduzindo assim o intervalo entre amostragens para quinze dias, adaptando a metodologia de acordo com as pragas de ocorrência regional (MAGALHÃES, 2004). As inspeções ocorreram em no mínimo 10\% das plantas úteis/propriedade, realizando-se caminhada em ziguezague e escolhendo aleatoriamente as amostras, analisando-se ao menos três ápices foliares de cada planta registrando-se em caso ou não de ocorrência.

Cultura Agronômica, Ilha Solteira, v.25, n.3, p.303-316, 2016 
As visitas realizadas tiveram duração média de uma hora e foram, em sua maioria, acompanhadas por técnicos agrícolas da Secretaria de Agricultura (SEAGRI) do município de Russas, Ceará, que realizam a assistência técnica de maneira contínua. Os dados e observações coletadas foram anotados e após síntese constituem este presente artigo.

\section{RESULTADOS E DISCUSSÃO}

A citricultura no município de Russas desenvolve-se principalmente através de indivíduos do sexo masculino, responsáveis pela implantação e condução dos principais aspectos agronômicos do pomar, possuindo em média 49 anos e composição familiar média de quatro pessoas, onde 56,66\% dos agricultores dedicam-se exclusivamente à propriedade e $15,15 \%$ dos familiares auxiliam nas atividades. As propriedades possuem área total média de 3,35 ha, variando de um a dez ha, havendo predominância de propriedades entre três e cinco hectares (47\%) (Figura 2), utilizando-se de maneira diversificada a área, sendo que $75 \%$ dos agricultores realizam cultivos concomitantes aos citros (Figura 3), em pequena escala e principalmente para subsidio familiar e comercialização nos mercados locais.

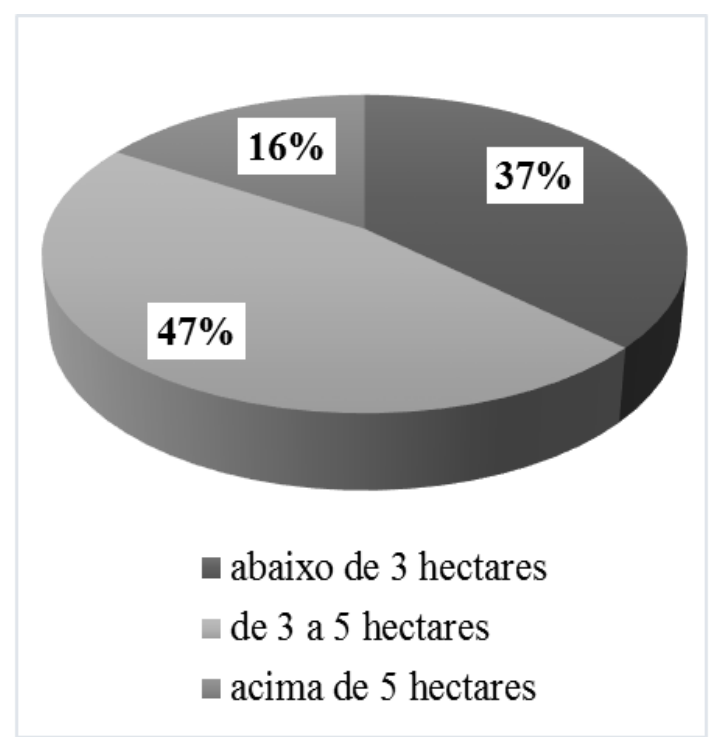

Figura 2. Distribuição das propriedades por área total, Russas, Ceará.

Ao analisar o sistema de produção dos citricultores familiares estudados, se torna notória a distinção entre estes e os modelos adotados nas grandes propriedades, onde especializa-se o cultivo em larga escala de uma determinada cultura (monocultivo/commodities), que geralmente compõe matéria prima pra exportação, a exemplo a soja (Glycine max), cultivada atualmente em larga escala em propriedades de grande porte da mesorregião do Vale do Jaguaribe. A integração das atividades produtivas, utilização da mão de obra familiar, e a gestão realizada pelos proprietários, onde toda renda advém predominantemente das práticas econômicas do próprio estabelecimento em áreas inferiores a quatro módulos fiscais evidenciam o caráter familiar das unidades avaliadas (BRASIL, 2006). É possível observar uma diversificação nas atividades agrícolas e pecuárias desenvolvidas, como ocorre na agricultura com um alto número de variedades 
cultivadas, (Figura 3), em contrapartida ao baixo número de plantas por espécie. Isso pode reduzir a aquisição externa de alimentos, proporcionando uma gama de alimentos saudáveis para a familia e nos mercados locais, através da comercialização do excedente, gerando a possibilidade de renda e melhoria na qualidade de vida (GUILHOTO, 2007).

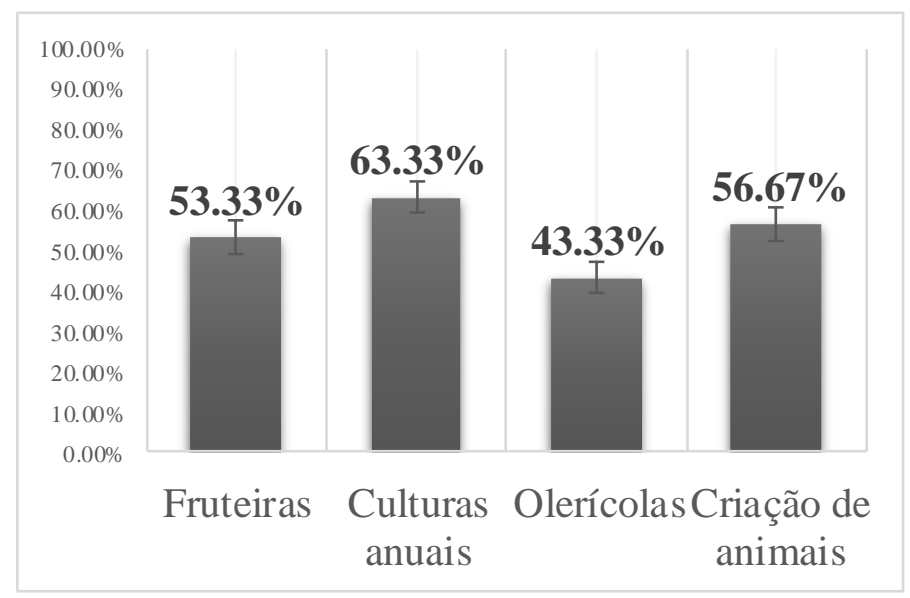

Figura 3. Atividades desenvolvidas em concomitância aos citros, Russas, Ceará.

As atividades desenvolvidas nas propriedades podem ser divididas entre a agricultura e a pecuária. Quanto aos cultivos realizados em concomitância aos citros, citam-se: fruteiras, cultivadas em cerca de 53,33\% das propriedades, principalmente cultivares de banana (Musa sp.) e manga (Mangirfera indica L.); culturas anuais $(63,33 \%)$, como o feijão (Vigna unguiculata L. Walp), milho (Zea mays L.) e mandioca (Manihot esculenta Crantz); e olerícolas $(43,33 \%)$, como tomate (Solanum lycopersicum L.), cebolinha (Allium fistulosum L.), e coentro (Coriandrum sativum L.). Algumas destas culturas são cultivadas em consórcio com os citros, aproveitando as entrelinhas dos pomares, principalmente culturas anuais e olerícolas. Elas podem funcionar como subsídio financeiro para manutenção do pomar cítrico em seu período de formação, principalmente por se constituírem em culturas de ciclo rápido e fácil comercialização em mercados locais. A pecuária desenvolvida pelos pequenos citricultores, baseia-se na criação de animais de pequeno e grande porte sem raça definida (aves, ovinos, caprinos e bovinos). A criação de animais pelos citricultores proporciona, além de alimento e renda complementar, insumos para a realização de adubações orgânicas, ou compostagens. Todos os pomares cítricos estudados caracterizam-se como de pequeno porte, variando em relação à área produtiva e ao número de plantas.

Constatou-se um número médio de 142 plantas por pomar, oscilando entre os menores índices, que são de um pomar constituído de 50 plantas em uma área produtiva de 0,12 ha, enquanto os maiores correspondem a 464 plantas em uma área de 0,52 ha. Os principais espaçamentos adotados são: $4 \mathrm{~m}$ x 3m (33\%), 5m x 4m (27\%) e/ou 5m x 3m (20\%). Os pomares representam em média $18 \%$ da área total da propriedade. $\mathrm{O}$ número de plantas por pomar apresentou-se compatível com a agricultura familiar desenvolvida na região, em face à diversidade de atividades e a constituição familiar observada, onde maior parte das atividades agropecuárias é realizada apenas com a mão de obra familiar disponível, 
limitando as dimensões das cadeias produtivas que podem vir a ser desenvolvidas.

Localmente predomina o cultivo de laranja doce, com $77 \%$ ou 3.885 mudas implantadas no período avaliado, o domínio da laranja [Citrus sinensis (L.) Osbeck] é atribuido pelos citricultores ao histórico local, muitos conviveram com a citricultura desde a infância, quando a atividade era conduzida por seus pais. As demais espécies adotadas são: limas ácidas (9\%, 454 mudas); tangerinas (5\%, 252 mudas), pomelo (4\%, 202 mudas) e limão (5\%, 252 mudas) (Figura 4). Analisando estes índices, constata-se que os 14\% de lima ácida e limão verdadeiro, são superiores aos índices nacionais de 5\%, enquanto o de laranja (77\%) é inferior aos nacionais de 89\% (IBGE, 2015).

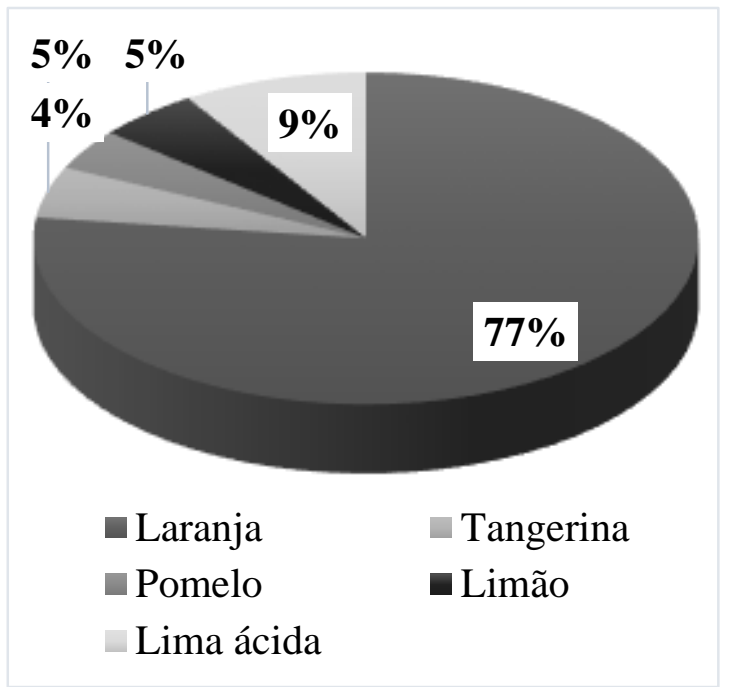

Figura 4. Distribuição das mudas cítricas implantadas por espécie, Russas, Ceará.

Constatou-se o maior número de plantio de mudas cítricas em 2013, quando implantou-se 40,7\% (2.057 mudas) do total observado em todo o período (2012/2014). A totalidade das implantações de tangerina, pomelo e limão, além do maior índice de implantação de limas ácidas (58,38\%, 216 mudas), também foram obtidos em 2013. Porém, a maior implantação de laranja doce ocorreu em 2012 (42,82\%, 1384 mudas) (Figura 5).

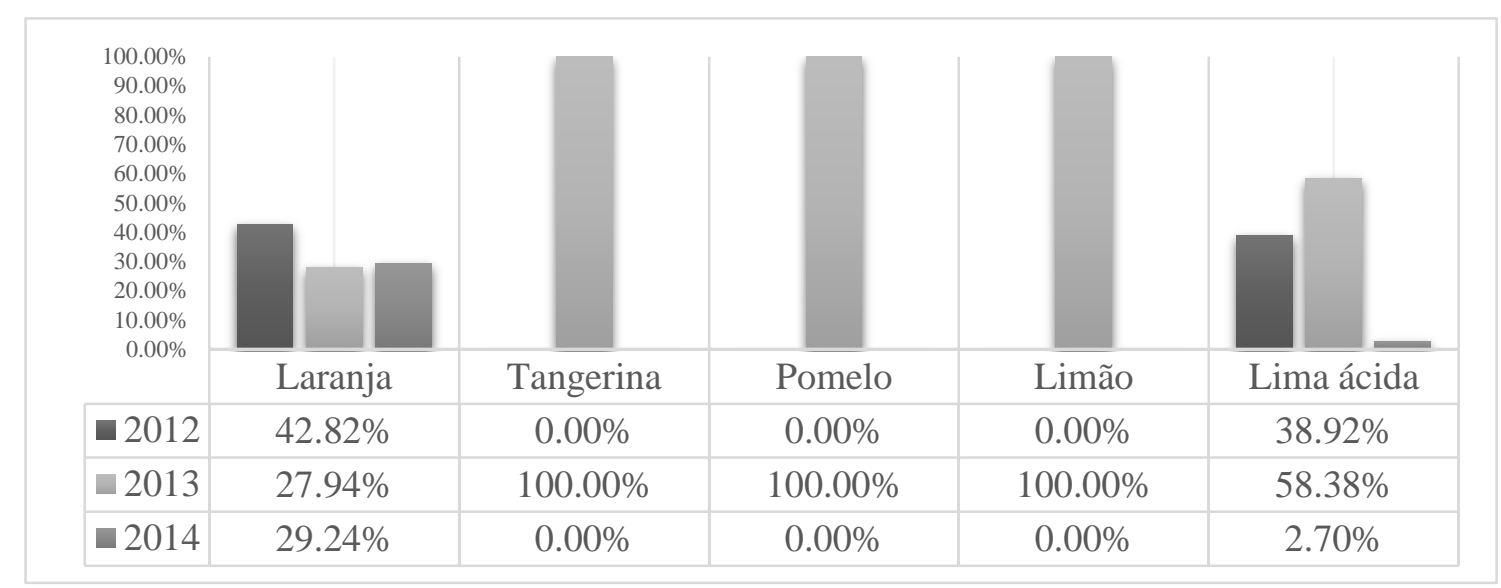

Figura 5. Distribuição das mudas cítricas implantadas por espécie/ano, Russas, Ceará.

Os pomares em estudo apresentavam alta diversificação na distribuição de cultivares, 
copa e porta-enxertos. Apresentando 17 diferentes cultivares de laranja doce [Citrus sinensis (L.) Osbeck], com percentuais variando de $2 \%$ a $10 \%$ cada cultivar, enquanto, nos principais polos citrícolas do país, os pomares baseiam-se na adoção de uma gama limitada de cultivares, como ocorre no estado de São Paulo (SP), onde a adoção de copas baseia-se nas cultivares "Pêra" (31,57\%) e "Valência" (27,30\%), principalmente sob o porta-enxerto "Limão Cravo (C. limonia Osbeck)" presente em 33,27\% das combinações copa/portaenxerto em campo (CDA, 2015). O limão cravo apresenta tolerância à seca; boa produtividade; produção e maturação precoces de frutos, porém, apresenta suscetibilidade à gomose de Phytophthora spp. e ao declínio. Com isso, a diversificação de porta-enxertos através de genótipos como Citrandarins (híbridos de microtangerinas, como as tangerinas Sunki ou Cleópatra, com trifoliatas), presentes em 67\% das combinações implantadas nos pomares estudados, tomam enorme importância (PIMENTEL et al., 2014). Os Citrandarins reúnem as qualidades das tangerinas, como tolerância ao declínio e à morte súbita dos citros, às qualidades dos trifoliatas, como imunidade à tristeza [Citrus tristeza vírus, (CTV)] e a resistência à gomose (Phytophthora spp.), além da formação de plantas de pequeno tamanho (ananicante), com elevada eficiência produtiva de frutos de alta qualidade (SCHAFER et al., 2001; POMPEU JUNIOR; BLUMER, 2011; POMPEU JUNIOR; BLUMER, 2014;), além de resistência à seca, principalmente em climas de semiárido Nordestino (BRITO et al., 2012; SOARES et al., 2015). As demais cultivares de portaenxertos utilizadas consistem no próprio limoeiro 'Cravo' (10\%), tangerineira 'Sunki tropical' (14\%) e citrumelo 'Swingle 4475' (9\%).

O levantamento das práticas agrícolas empregadas nas propriedades foi dividido entre práticas de correção e adubação (realização de análise do solo, realização de calagem ou gessagem, adubação química ou orgânica; principais insumos e práticas), tratos culturais, irrigação, ocorrência e controle de pragas. Constatou-se que a maioria dos agricultores $(76,67 \%)$ não realizavam análises de solo periodicamente, enquanto apenas 23,33\% realizaram, o que poderia servir como referência para o manejo racional do solo e para a sua devida correção e adubação, visto que a região em que inserem-se os pomares predomina a ocorrência de Vertissolos (SiBCS). Esses solos são de boa fertilidade, porém, com limitações quanto ao uso no período chuvoso, quando tornam-se "pesados" devido ao aumento da umidade, necessitando de manejo adequado principamente em condições semiáridas, onde a baixa infiltração de água e a drenagem lenta favorecem seu enchacarmento, que na presença de sais na irrigação, podem gerar sua salinização. Quanto à baixa realização das análises de solo, os agricultores atribuem à pouca ou nenhuma assistência técnica recebida, além da presença de apenas um laboratório de analises na mesorregião. Disso resulta que não foram constatadas em nenhuma propriedade práticas de correção, como calagem e gesagem, e que poderiam otimizar e condicionar o solo para a cultura dos citros. A maior parcela dos agricultores utilizou compostos orgânicos, em sua maioria estercos e restos vegetais, como adubação de fundação e cobertura (Figura 6).

Cultura Agronômica, Ilha Solteira, v.25, n.3, p.303-316, 2016 


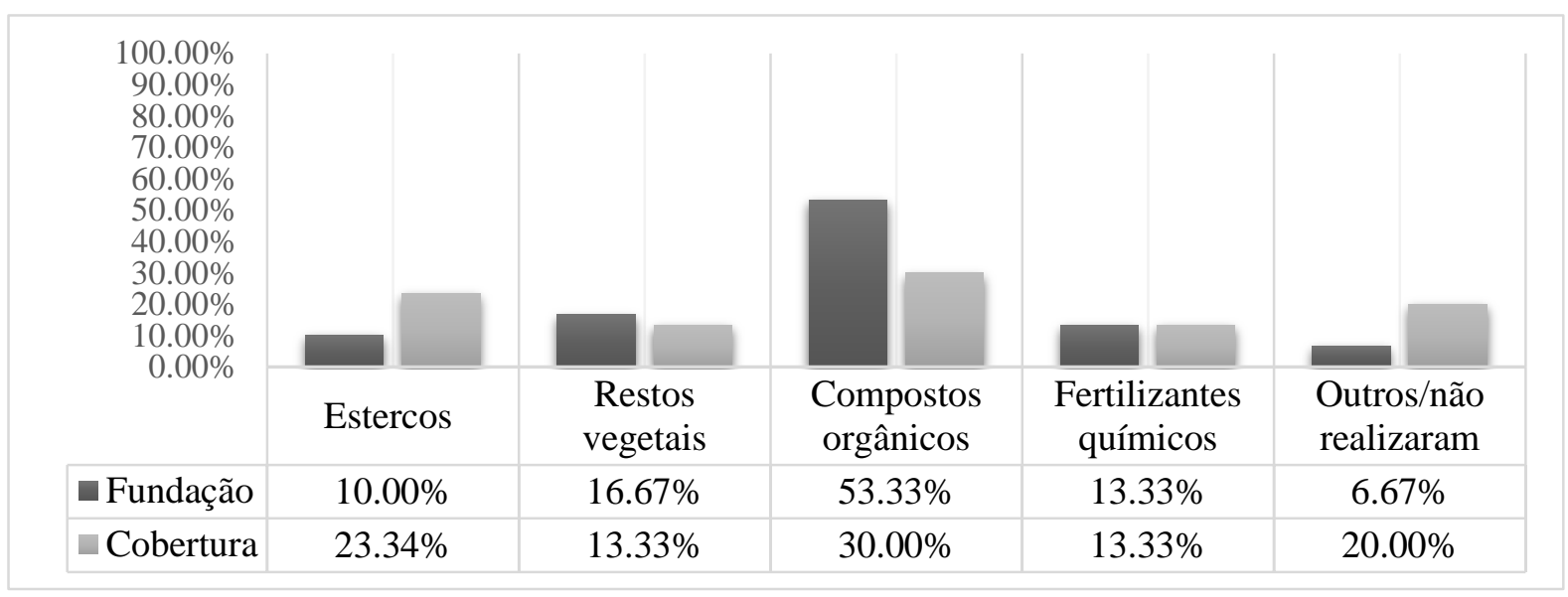

Figura 6. Distribuição dos insumos utilizados nas adubações dos pomares, Russas, Ceará.

Os insumos para adubação orgânica (estercos/restos vegetais) consistiam em insumos de fácil aquisição, encontrados ou produzidos na propriedade. Os compostos mais empregados, como a "bagana de carnaúba" e estercos em geral, foram adquiridos localmente ou produzidos na própria propriedade, como no caso dos estercos oriundos das atividades pecuárias desenvolvidas por parte dos agricultores estudados. Já os restos vegetais das palhas de carnaúba (Copernícia prunífera), chamada localmente de "bagana de carnaúba", era adquirida em grande quantidade em períodos específicos do ano, uma vez que a oferta gira em função do extrativismo sazonal para aproveitamento da cera, subproduto de alto valor econômico (MARINHO JÚNIOR; MARQUES, 2014).

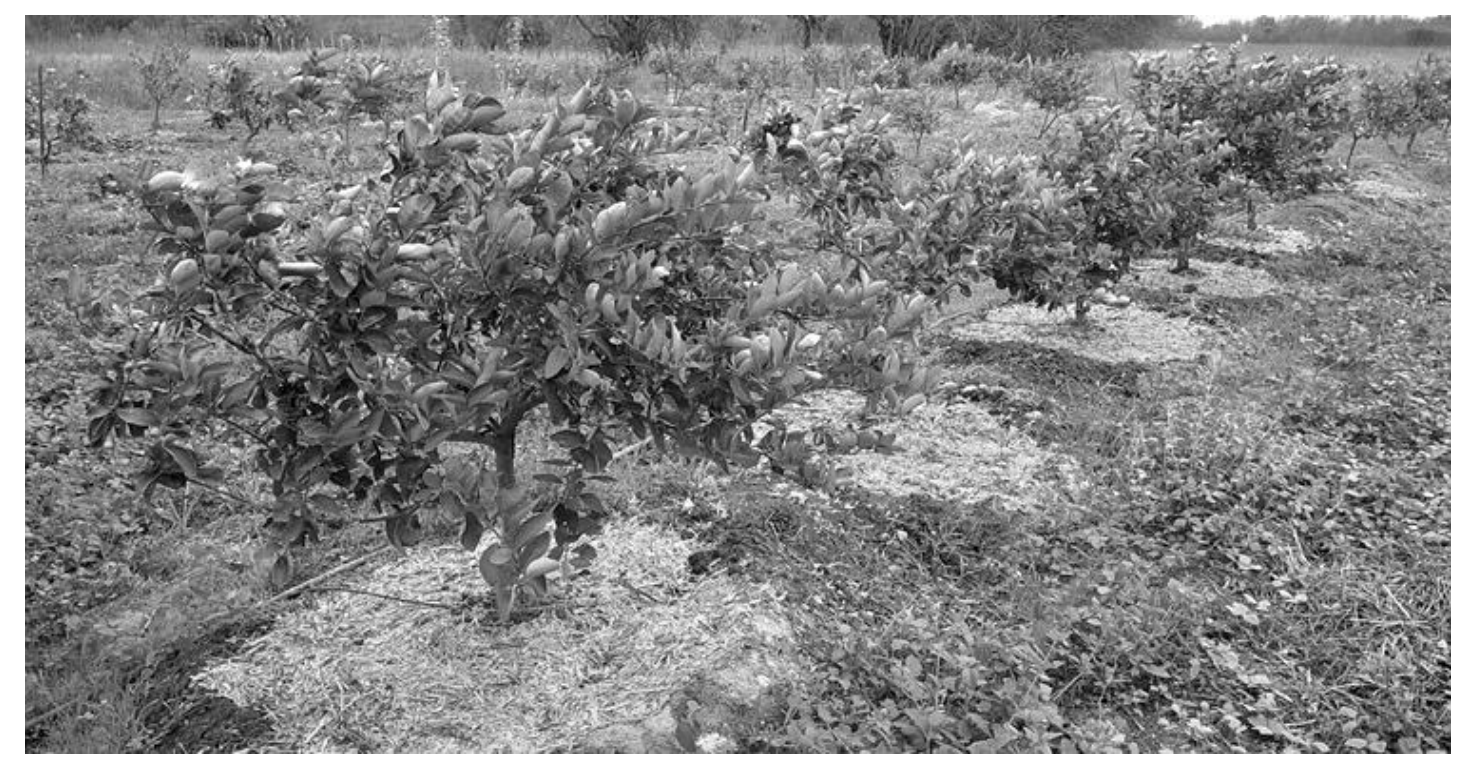

Figura 7. Utilização de restos vegetais de carnaúba (Copernicia prunífera) como cobertura morta em bacias de capitação de pomar cítrico. Pau Branco. Russas, Ceará.

Os tratos culturais resumem-se à eliminação de brotos ladrões e ramos verticalizados, a realização de capina e coroamento em uma circuferência de cerca de 1,5 m (bacias de captação) em torno da planta, respeitando-se um monte próximo ao caule. Parte dos citricultores adicionaram posteriormente cobertura morta $(65 \%)$ à base de bagana de 
carnaúba (Figura 7).

Por sua vez, não se registrou controle químico das plantas daninhas ou espontâneas, permanecendo apenas a realização do roço e/ou capina das vegetações espontâneas, nas entre plantas e entre linhas, quando necessário. Por último, 20\% dos agricultores realizaram cultivos intercalares (por exemplo cebolinha, coentro ou milho) nas entrelinhas (Figura 8).

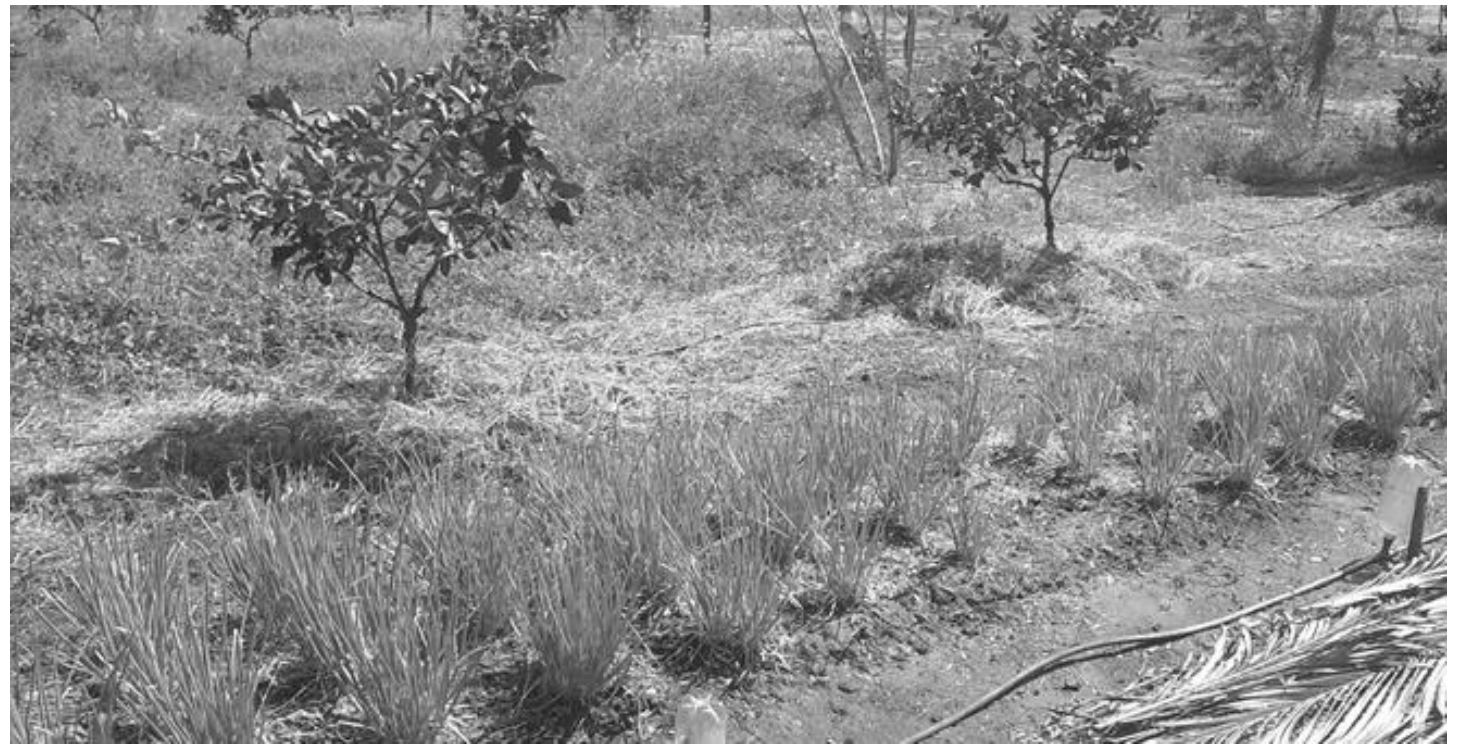

Figura 8. Cultivo de cebolinha (Allium fistulosum) nas entrelinhas do pomar cítrico. Poço Verde. Russas, Ceará

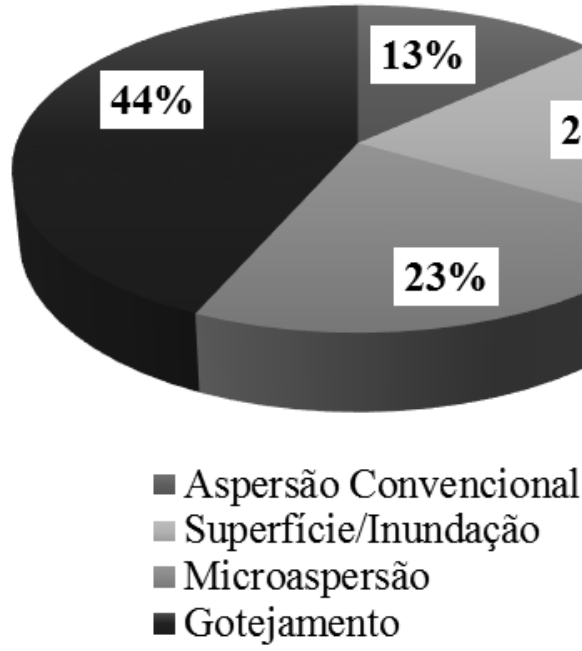

Figura 9. Distribuição dos sistemas de irrigação adotados nos pomares, Russas, Ceará.

O principal sistema de irrigação utilizado pelos agricultores é o localizado por gotejamento (Figura 9), adotado em cerca de 43,33\% dos pomares. A adoção da irrigação localizada vem crescendo destacadamente no cenário mundial mostrando-se um mercado promissor, quando comparado aos outros sistemas de irrigação. Na irrigação localizada por gotejamento, o volume de água aplicado é reduzido e restrito a uma parcela de solo (bulbo úmido), reduzindo-se as perdas por evaporação e assim o consumo hídrico para manutenção 
da cultura (COELHO et al., 2006). Outros métodos também foram constatados, como o sistema por aspersão convencional e a irrigação por superfície, $20 \%$ dos pomares ainda eram irrigados através da inundação das bacias de capitação das plantas, prática realizada historicamente na região do Vale do Jaguaribe, e que geralmente causa acúmulo de água no colo da planta de citros, podendo favorecer a proliferação de fitopatógenos, além de consumir um maior volume de água em comparação ao método mais adotado.

Constatou-se tendência para produção orgânica por parte dos citricultores no presente estudo. Podemos destacar o emprego da adubação orgânica, através do uso de insumos locais ou disponíveis na propriedade; gestão hídrica através do uso diversificado da água disponível, que abastece o sistema irrigação e fornece água para as atividades domésticas; utilização de defensivos naturais, à base de plantas com características inseticidas e/ou repelentes, como calda de fumo e Neem indiano (Azadirachta indica), no convívio com a praga (Figura 10).

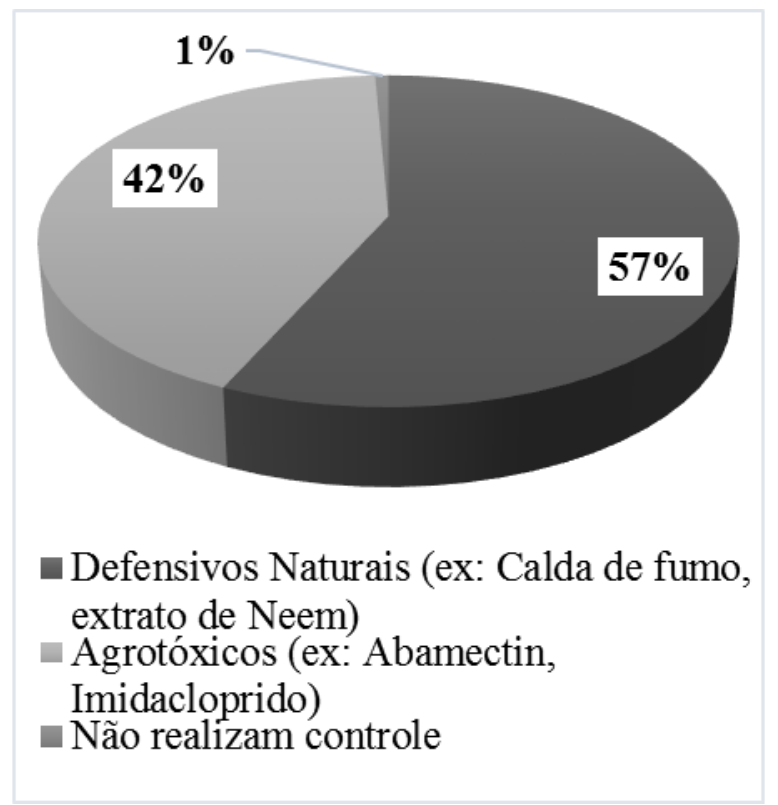

Figura 10. Métodos e insumos utilizados pelos agricultores no controle de pragas dos pomares de citros, Russas, Ceará.

Por outro lado, alguns desafios necessitam atenção visto que através de amostragens periódicas constatou-se alta ocorrência de minadora-das-folhas dos citros (Phyllocnistis citrella Station.) e cochonilhas em geral (Figura 11), que podem ser manejadas com a devida orientação técnica. Porém, não se registrou pragas-chave como mosca negra (Aleurocanthus woglum), nem sintomas de gomose (Phytophthora spp.), atribuindo-se ao emprego de porta-enxertos resistentes e atenção dos agricultores no manejo (ALMEIDA; PASSOS, 2011). 


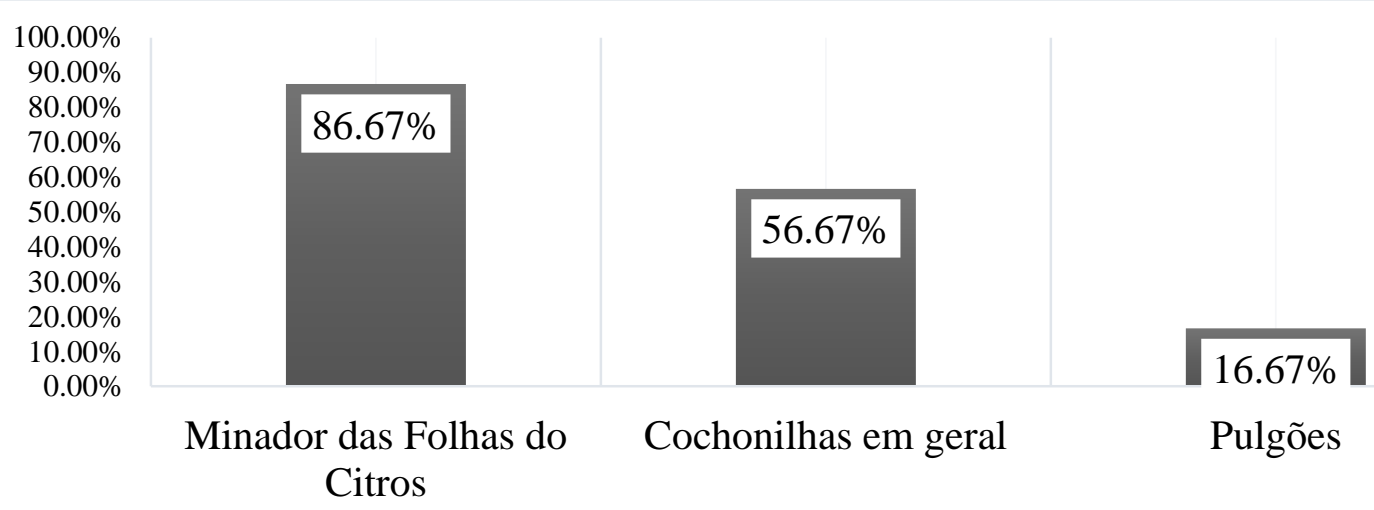

Figura 11. Ocorrência de pragas registradas nos pomares e citros durante o período do trabalho, Russas, Ceará

Os agricultores utilizam diversas caldas e extratos no manejo de insetos praga. O extrato de citronela (Cymbopogon winterianus Jowitt) foi o único produzido e distribuído pelo NPC - Núcleo Discente de Pesquisa em Citros, do Instituto Federal do Ceará (IFCE), enquanto os mais utilizados são produzidos pelos próprios agricultores, como o extrato de Neem (Azadirachta indica A. Juss) (70\%) e Calda de fumo + sabão de côco (55\%). Nas propriedades que não realizam amostragens periódicas o uso ocorre semanal, ou quinzenalmente, enquanto nas sete propriedades que adotam amostragens como referências as intervenções são pontuais, quando ocorre aumento significativo na densidade populacional da larva minadora dos citros (LMC) ou cochonilhas. As aplicações são através de pulverização foliar utilizando bomba costal manual. A eficiência dos métodos ainda não é quantificada, porém a ausência do uso de agrotóxicos, associada às demais práticas, induzem menores incidências de insetos nocivos, quando comparados aos pomares convencionais, como aponta a teoria da trofobiose (CHABOUSSOU, 1987). Essa teoria assinala que a utilização de fertilizantes sintéticos e agrotóxicos torna a planta mais suscetível a doenças, principalmente pela presença de aminoácidos livres, enquanto a adoção de práticas orgânicas, que visem o desenvolvimento da biota do solo, torna a planta mais resistente (PRIMAVESI, 2014).

Não se avaliou a realização de empréstimos junto a entidades financeiras, porém, é possível constatar a baixa tecnologia empregada atualmente na citricultura regional, o que através de acesso ao crédito poderia possibilitar uma exploração mais tecnificada e intensiva, resultando em melhores produtividades e rentabilidade para os pequenos (as) citricultores (as). Como os pomares avaliados haviam sido implantados entre os anos de 2012 e 2014 não se constatou produção em níveis satisfatórios para comercialização no período de realização da pesquisa, apesar de parte dos citricultores avaliados já comercializarem frutos de outras fruteiras nos mercados do próprio município.

\section{CONCLUSÃO}

A citricultura desenvolvida na agricultura familiar de Russas-CE sobressai-se pela alta diversificação de cultivares, copa e porta-enxerto empregadas, diversidade de atividades 
concomitantes ao cultivo de citros numa mesma propriedade, além da baixa incidência de pragas e doenças chave, potenciais que possibilitam o desenvolvimento de técnicas de transição agroecológica. Citam-se como pontos fracos, o baixo poder aquisitivo e a ausência de assistência técnica e extensão rural de qualidade, aspectos que podem vir a sanar-se com assistência técnica e disponibilidade de crédito rural junto às instituições financeiras.

\section{AGRADECIMENTOS}

À Embrapa Mandioca e Fruticultura Tropical (Cruz das Almas, Bahia), Embrapa Semiárido (Petrolina, Pernambuco), Secretaria de Agricultura de Russas (SEAGRI RUSSAS) e Núcleo de Pesquisa em Citros (NPCitrus).

\section{REFERÊNCIAS BIBLIOGRÁFICAS}

ALMEIDA, C. O.; PASSOS, O. S. Citricultura brasileira: em busca de novos rumos desafios e oportunidades na região Nordeste. 1. ed. Cruz das Almas, BA: Embrapa Mandioca e Fruticultura Tropical, 2011. 160 p.

BRASIL. Lei. 11.326, de 24 de julho de 2006. Estabelece as diretrizes para a formulação da Política Nacional da Agricultura Familiar e Empreendimentos Familiares Rurais. Diário Oficial da União, Brasília, DF, v. 25, p. 1-4, 2006.

BRITO, R. B. F.; SOUZA, L. D.; SAMPAIO, A. H. Determinação da relação solo planta em pomar de citros com diferentes combinações copa/porta-enxerto. In: JORNADA CIENTÍFICA, 6., 2012, Cruz das Almas. Anais... Cruz das Almas: Embrapa Mandioca e Fruticultura, 2012. p. 142.

CHABOUSSOU, F. Plantas doentes pelo uso de agrotóxicos: a teoria da trofobiose. Porto Alegre: LPM, 1987. 256 p.

COELHO, E.; COELHO FILHO, M.; SIMÕES, W.; COELHO, Y. S. Irrigação em citros nas condições do nordeste do Brasil. Laranja, Cordeirópolis, v. 27, n. 2, p. 297-320, 2006.

COORDENADORIA DE DEFESA AGROPECUÁRIA DO ESTADO DE SÃO PAULO CDA. Consolidado da Citricultura Paulista: $2^{\circ}$ Semestre 2015. São Paulo, SP: Coordenadoria de Defesa Agropecuária do Estado de São Paulo, 2015. 522 p.

CUNHA SOBRINHO, A. P.; MAGALHÃES, A. F. J.; SOUZA, A. S.; PASSOS, O. S.; SOARES FILHOS, W. S. A Cultura do Citros. Brasília, DF: Embrapa Informação Tecnológica, 2013. v. 1. 399 p.

GUILHOTO, J.; ICHIHARA, S. M.; SILVEIRA, F. G.; DINIZ, B. P. C.; AZZONI, C. R.; MOREIRA, G. R. C. A Importância da agricultura familiar no brasil e em seus estados. In: Encontro Nacional de Economia, 35., 2007, São Paulo. Anais... São Paulo: ANPECAssociação Nacional dos Centros de Pós-graduação em Economia, 2007. p. 1-18.

Cultura Agronômica, Ilha Solteira, v.25, n.3, p.303-316, 2016 
INSTITUTO BRASILEIRO DE GEOGRAFIA E ESTATÍSTICA - IBGE. Pesquisa mensal de previsão e acompanhamento das safras agrícolas no ano civil. Levantamento Sistemático da Produção Agrícola, Rio de Janeiro, RJ. v. 29, n. 1, p.56-83, 2015.

MARINHO JÚNIOR, J. A.; MARQUES, L. G. A. Cera de Carnaúba. Cadernos de Prospecção, v. 2, n. 1, p. 36, 2014.

MAGAlHÃES, A. F. J. (Ed.). Cultivo dos Citros. Cruz das Almas, BA: Embrapa Mandioca e Fruticultura Tropical, 2004. 183 p.

MARCONI, M. A.; LAKATOS, E. M. Técnicas de pesquisa. 6. ed. São Paulo: Atlas, v. 4, 2007. 289 p.

PASSOS, O. S.; SOARES FILHO, W. S.; BARBOSA, C. J.; CUNHA SOBRINHO, A. P. Clones de laranjeira 'DE RUSSAS'. Cruz das Almas, BA: Embrapa Mandioca e Fruticultura, 2013. 4 p. (Folder/Folheto/Cartilha).

PIMENTEL, U. V.; MARTins, A. B. G.; BARBOSA, J. C.; CAVAllaRI, L. D. L. Nutrição do porta-enxerto 'Flying Dragon'. Revista Brasileira de Fruticultura, Jaboticabal, v. 36, n. 2, p.495-502, 2014.

PIO, R. M.; FIGUEIREDO, J.O.; STUCHI, E.S.; CARDOSO, S.A.B. Variedades copas. In: MATTOS JUNIOR, D.; DE NEGRI, J. D.; PIO, R. M.; POMPEU JÚNIOR, J. (Ed.). Citros. Campinas, SP: Instituto Agronômico e Fundag, 2005. cap. 3, p. 37-60.

POMPEU JUNIOR, J.; BLUMER, S. Citrandarins e outros híbridos de trifoliata como porta-enxertos para laranjeira Valência. Citrus Research \& Technology, Cordeirópolis, v. 32, n. 3, p.133-138, 2011.

POMPEU JUNIOR, J.; BLUMER, S. Híbridos de trifoliata como porta-enxertos para laranjeira Pêra. Pesquisa Agropecuária Tropical, Goiânia, v. 44, n. 1, p.9-14, 2014.

PRIMAVESI, A. Pergunte ao solo e às raízes: uma análise do solo tropical e mais de 70 casos resolvidos pela agroecologia. 1. ed. São Paulo: Nobel, 2014. 272 p.

SANTOS FILHO, H. P.; MAGALHÃES, A. F. J.; COELHO, Y. S. Citros: o produtor pregunta, a Embrapa responde. 1. ed. Brasília, DF: EMBRAPA, 2005. 205 p.

SCHAFER, G.; BASTIANEL, M.; DORNELLES, A. L. C. Porta-enxertos utilizados na citricultura. Ciência Rural, Santa Maria, v. 31, n. 4, p.723-733, 2001.

SOARES, L. A. A.; BRITO, M. E. B.; FERNADES, P.; LIMA, G. S.; SOARES FILHO, W. S.; OLIVEIRA, E. S. Crescimento de combinações copa-porta-enxerto de citros sob estresse hídrico em casa de vegetação. Revista Brasileira de Engenharia Agrícola e Ambiental, Campina Grande, v. 19, n. 3, p.211-217, 2015. 